\title{
Rare anatomical variation in transverse sinuses (duplication on right, hypoplasia of left) falsely mimicking transverse sinus thrombosis probably due to resultant slow flow
}

\author{
Naresh Monigari, ${ }^{1}$ Anirudda Deshpande, ${ }^{2}$ Veena Vedartham, ${ }^{1}$ Murali Nalabothu ${ }^{1}$
}

${ }^{1}$ Department of Medicine, Kasturba Medical College Hospital, Manipal, Karnataka, India

${ }^{2}$ Department of Neurology, Kasturba Medical College Hospital, Manipal, Karnataka, India

\section{Correspondence to} Dr Anirudda Deshpande, dr.aniruddha.deshpande@ gmail.com

\section{DESCRIPTION}

We report the case of a 30-year-old, 2 weeks postpartum female, with a history of right temporal headache, intermittent, holocranial in nature, moderate intensity with associated nausea and vomiting when headache was severe. Symptoms were worse since the past 10 days. Neurological examination including funduscopy was unremarkable. A probable diagnosis of transformed migraine without aura was made; however, in view of the new onset headache during postpartum status MRI of the brain was performed to rule out the possibility of cortical venous thrombosis. MRI of the brain showed the absence of flow void in the right transverse sinuses (figure 1), MR venogram showed normal filling of the entire venous system. However, there was a presence of bifid transverse sinus on the right side, hypoplastic left sinus with normal flow-related enhancement on the left side (figures 2-4). This was a rare incidental finding. Hypoplasia of the left transverse sinus is a wellknown anatomical variation. Two previous studies showed the incidence of left hypoplastic sinus to be $24 \%{ }^{1}$ and $31 \%{ }^{2}$ of normal asymptomatic population on MR venography. Duplication of right transverse sinus is seen in our patient which to the best of our knowledge has not been reported previously.

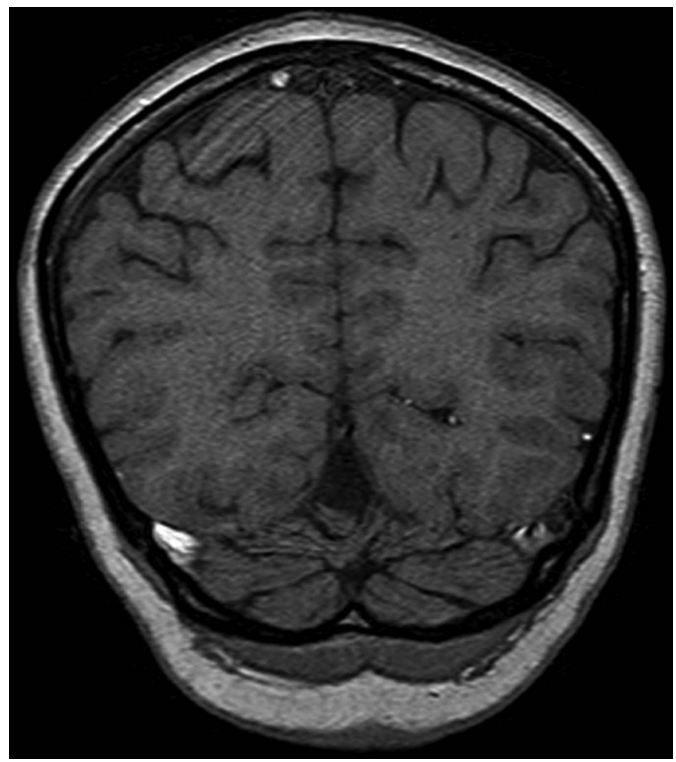

Figure 1 Brain MRI T1-weighted coronal sequence showing the absence of flow void in right transverse sinus.

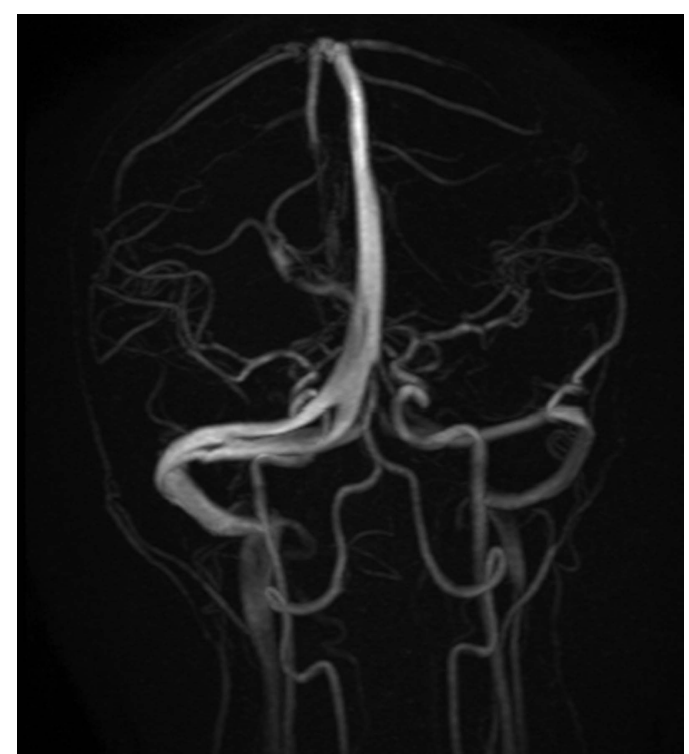

Figure 2 MR venography demonstrating the duplication of right transverse sinus with hypoplastic left transverse sinus.

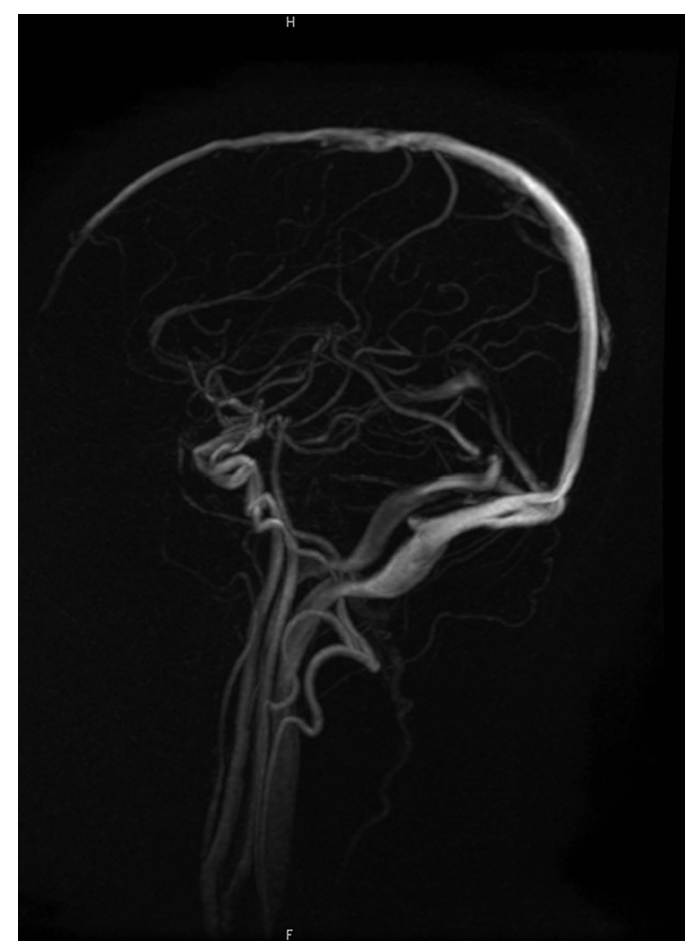

Figure 3 MR venography demonstrating the duplication of right transverse sinus with hypoplastic left transverse sinus. 


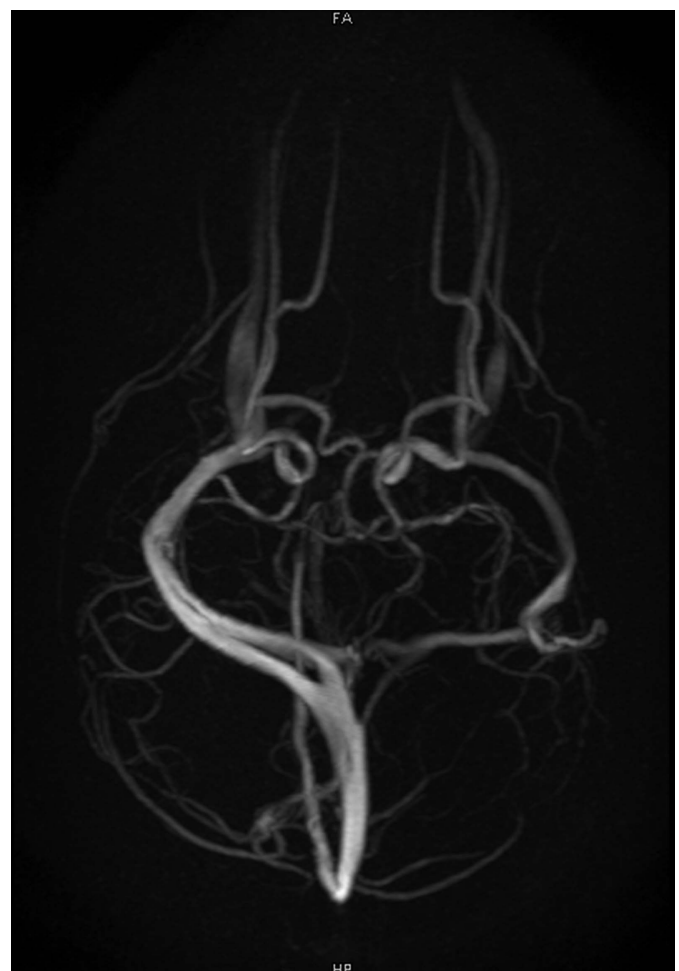

Figure 4 MR venography demonstrating the duplication of right transverse sinus with hypoplastic left transverse sinus.

We postulate that the bifid transverse sinus may slow the venous flow in the transverse sinus and this may give rise to a false MRI finding of absent flow void in the same, hence mimicking transverse sinus thrombosis. This is all the more logical in this case as left transverse sinus is hypoplastic on the left side therefore making the right transverse sinus the major path of drainage of venous blood to internal jugular vein.
In view of frequent presence of an asymptomatic dural venous sinus anatomical variation these should be interpreted with caution and should not to be mistaken with cortical sinus thrombosis. The patient was treated for transformed migraine with topiramate with which she showed significant improvement in her symptoms.

\section{Learning points}

- Duplication of transverse sinus is a rare congenital abnormality.

- It may mimic transverse sinus thrombosis probably as a result of slow flow.

- Duplication is a rare normal anatomical variation of transverse sinus, which may or may not be associated with hypoplasia of the other side.

Acknowledgements The authors would like to thank Dr Suryanarayan Rao, Professor and Head, Department of Neurology, Kasturba Medical College, Manipal, Karnataka, India.

Contributors NM made substantial contributions to the conception or design of the work, acquisition, analysis and interpretation of the data. AD and VV were involved in drafting the manuscript or revising it critically for important intellectual content. MN and VV approved the final version to be published.

Competing interests None.

Patient consent Obtained.

Provenance and peer review Not commissioned; externally peer reviewed.

\section{REFERENCES}

1 Alper F, Kantarci M, Dane $S$, et al. Importance of anatomical asymmetries of transverse sinuses: an MR venographic study. Cerebrovasc Dis 2004;18:236-9.

2 Ayanzen RH, Bird CR, Keller PJ, et al. Cerebral MR venography: normal anatomy and potential diagnostic pitfalls. AJNR Am J Neuroradiol 2000;21:74-8.

Copyright 2014 BMJ Publishing Group. All rights reserved. For permission to reuse any of this content visit http://group.bmj.com/group/rights-licensing/permissions.

BMJ Case Report Fellows may re-use this article for personal use and teaching without any further permission.

Become a Fellow of BMJ Case Reports today and you can:

- Submit as many cases as you like

- Enjoy fast sympathetic peer review and rapid publication of accepted articles

- Access all the published articles

- Re-use any of the published material for personal use and teaching without further permission

For information on Institutional Fellowships contact consortiasales@bmjgroup.com

Visit casereports.bmj.com for more articles like this and to become a Fellow 